\title{
ANALISA FAKTOR-FAKTOR YANG MEMPENGARUHI KETEPATAN WAKTU PELAPORAN KEUANGAN PERUSAHAAN YANG TERDAFTAR DI BURSA EFEK INDONESIA
}

\author{
Mari Oktavia* dan Kennardi Tanujaya* \\ *Jurusan Akuntansi, Fakultas Ekonomi \\ Universitas Internasional Batam \\ *Email: mari.oktavia@yahoo.com; kennardi.tanujaya@uib.ac.id
}

\begin{abstract}
This research investigates factors affecting timeliness of annual corporate financial reporting in Indonesia. The sample of the research is a company listed on Indonesia Stock Exchange (BEI) in 2012-2017. Company size, company profitability, company age, leverage, audit committee independence, member audit committee, audit committee experience, auditor type, audit report, auditor rotation and audit opinion used as variable independent.

The sample of this research includes 335 company on BEI with 1.675 data. Data obtained from financial statement year ended 2012 until 2017 and panel-regression test to examine the study hypotheses.

This reaearch found the average time company needs 120 days for issuing financial report. Variable company age and audit report have significant positive impact on timeliness of financial. Audit committee independent and member audit committee have significant negative impact on timeliness. However variable company size, company profitability, audit committee experience, auditor type, auditor rotation and audit opinion had no effect significant toward timeliness financial report.
\end{abstract}

Keywords : timeliness, company size, profitability, company age, leverage, audit committee independent, member audit committee, audit committee experience, auditor type, audit report, auditor rotation, audit opinion

\section{PENDAHULUAN}

Salah satu catatan tentang informasi keuangan adalah laporan keuangan. Laporan keuangan digunakan sebagai penggambaran kinerja perusahaan pada satu periode akuntansi dan menjadi pertimbangan pembuatan dan pengambilan keputusan. Laporan keuangan merupakan metode terbaik untuk memenuhi kebutuhan pengguna informasi akuntansi, serta dapat menggambarkan keadaan ekonomi pada satu periode akuntansi (Al-Juaidi \& AlAfifi, 2016).

Ketepatwaktuan merupakan indikator yang penting dalam menyajikan laporan keuangan kepada publik. Penyajian laporan keuangan dengan tepat waktu sangat diharapkan agar informasi dalam laporan tidak kehilangan manfaatnya ( $\mathrm{Ha}$,
Hung, \& Phuong, 2018). Laporan yang bermanfaat harus memiliki 4 kriteria, yaitu relevan, andal dapat dipahami, serta dapat dibandingkan (Ohaka \& Akani, 2017).

Pengungkapan keuangan yaitu pelepasan informasi keuangan secara sengaja dalam rangka untuk menginformasikan para pemangku kepentingan. Pengungkapatn keuangan meliputi laba bersih tahun sebelumnya, pertemuan direksi, pembagian dividen dan informasi lainnya menjadi bahan pertimbangan pengambilan keputusan bagi investor (Al-Juaidi \& Al-Afifi, 2016). Kebanyakan para akuntan, manajemen, investor dan pengguna informasi percaya bahwa tepat waktu adalah hal penting dalam pengungkapan informasi, sehingga 
pengungkapan harus dilakukan dengan tepat waktu (Dyer \& McHugh, 1975).

Ketepatan waktu merupakan faktor penting yang dapat mempengaruhi pengambilan keputusan. Masih ada perusahaan publik atau emiten yang secara tidak tepat pada waktunya dalam penyampaian laporan keuangan tahunan sehingga perlu ada penelitian lebih lanjut di Indonesia. Keterlambatan penyampaian laporan keuangan masih terjadi hingga saat ini, berdasarkan informasi Ipotnews pada tanggal 20 Juli 2018, kasus tersebut adalah "Tunggak Laporan Keuangan, BEI Hentikan Sementara Perdagangan 10 Saham".

Berdasarkan kasus di atas masih terjadi penundaan dalam penyampaian laporan keuangan di Indonesia hingga saat ini padahal informasi keuangan sangatlah penting disajikan dengan tepat waktu. Adapun beberapa dampak yang akan terjadi pada perusahaan yang tidak ontime seperti informasi yang disajikan tidak relevan lagi, akan dikenakan sanksi tertulis maupun administrasi, terlambat dalam penyampaian SPT tahunan sehingga akan dikenai denda atas telat penyampaian SPT, semakin menurun tingkat kepercayaan investor ataupun pengguna informasi terhadap perusahaan yang telat dan lainnya. Oleh karena itu penulis ingin meneliti dan mengetahui determinan yang dapat mempengaruhi keterlambatan dalam penyampaian serta penerbitan laporan keuangan.

Tujuan dari penelitian untuk menjelaskan faktor-faktor yang menyebabkan terjadinya penundaan dari penerbitan laporan keuangan. Manfaat dari penelitian ini yaitu dapat menjadi dasar ataupun referensi bagi pihak manajemen, investor, KAP dan akademisi untuk mengetahui determinan apa yang mempengaruhi ketepatan waktu dalam penyampaian laporan keuangan ke OJK dan publik serta sebagai pedoman untuk meningkatkan tingkat ketergantungan dan keandalan publik terhadap informasi yang disajikan oleh perusahaan melalui laporan keuangan tahunan.

\section{KAJIAN LITERATUR DAN PENGEMBANGAN HIPOTESIS}

Courtis (1976) meneliti hubungan karakteristik perusahaan dan ketepatwaktuan dari pelaporan keuangan entitas yang tercantum di Selandia Baru. Karakteristik perusahaan yang digunakan meliputi ukuran perusahaan, profitabilitas, umur perusahaan, jenis industri, jumlah halaman laporan tahunan dan jumlah pemengang saham. Hasil penelitian menunjukkan profitabilitas memiliki hubungan signifikan terhadap ketepatwaktuan, sedangkan umur dan ukuran perusahaan dan tidak memiliki kaitan dengan ketepatan waktu dalam pelaporan keuangan.

Dyer dan McHugh (1975) meneliti dengan sampel 120 perusahaan yang terdapat di SEE (Sydney Stock Exchange). Determinan yang diteliti mengenai ukuran perusahaan, profitabilitas dan financial year-end. Penelitian tersebut menemukan hubungan signifikan antara ukuran perusahaan dan financial year-end dengan ketepatwaktuan pelaporan keuangan, namun profitabilitas tidak memiliki hubungan terhadap ketepatan waktu dari pelaporan keuangan.

Keterlambatan audit dan keterlambatan pelaporan keuangan perusahaan yang terdapat dalam Bahrain Stock Exchange yang diteliti oleh Al-Ajmi (2008) menemukan jenis auditor tidak berpengaruh berkaitan terhadap keterlambatan pelaporan. Namun leverage, profitabilitas perusahaan dan ukuran entitas memberikan efek signifikan terhadap keterlambatan pelaporan.

\section{Ketepatan Waktu Pelaporan Keuangan}

Kerangka konseptual pelaporan keuangan berdasarkan standar akuntansi mengakui timeliness adalah karakteristik yang menentukan infomasi yang relevan (Al-Juaidi \& Al-Afifi, 2016). Ismail dan Chandler (2004) menyatakan pengguna 
informasi membutuhkan info keuangan yang tepat waktu untuk memutuskan investasinya pada suatu perusahaan, pengungkapan informasi yang tidak ontime dapat menyebabkan informasi tidak efisien bagi pengguna informasi.

Peraturan Otoritas Jasa Keuangan(OJK) nomor 29/POJK.04/2016 menyatakan bahwa:

"Emiten atau Perusahaan Publik wajib menyampaikan Laporan Tahunan kepada Otoritas Jasa Keuangan paling lambat pada akhir bulan keempat setelah tahun tutup buku berakhir. Dalam hal Emiten atau Perusahaan Publik memperoleh pernyataan efektif untuk pertama kali dalam periode setelah tahun buku berakhir, Emiten atau Perusahaan Publik wajib menyampaikan laporan tahuanan kepada Otoritas Jasa Keuangan paling lambat pada tanggal pemanggilan RUPS tahunan (jika ada)".

Penyampaian laporan keuangan tahunan kepada OJK melaui Sistem Pelaporan Elektronik (SPE) yang dapat diakses melalui website http://spe.ojk.go.id atau alamat lain yang ditetapkan OJK.

Pelaporan keuangan yang tetap waktu adalah hal yang sangat penting, apabila infomasi tersebut tidak tepat waktu akan menyebabkan pengguna informasi kehilangan manfaat dari informasi tersebut dan dapat menyebabkan kesalahan dalam pengambilan keputusan (Hamidi \& Rasouli, 2016). Tujuan utama dari laporan keuangan perusahaan yaitu memberikan informasi kepada pengguna informasi dalam pengambilan keputusan (Al-Ajmi, 2008).

\section{Ukuran Perusahaan}

Ukuran perusahaan merupakan salah satu faktor untuk menujukkan skala suatu perusahaan. Perusahaan dengan skala besar akan lebih menjaga image agar tetap dinilai bagus oleh masyarakat dan investor, sehingga perusahaan akan berusaha untuk menyampaikan laporan keuangan dengan tepat pada waktunya (Khasharmeh \& Aljifri, 2010).

Penelitian terdahulu yang menemukan ukuran berpengaruh signifikan negatif yaitu Adebayo dan Adebiyi (2016), Akle (2011), Al-Ajmi (2008), Dyer dan McHugh (1975), Ismail dan Chandler (2004), Ohaka dan Akani (2017) serta Oussii dan Taktak (2016). Sedangkan yang menemukan hubungan signifikan positif yaitu Afify (2009), Ahmed (2003) Pourali et al., (2013), Wang dan Song (2006).

$\mathrm{H}_{1}$ : Ukuran perusahaan berpengaruh signifikan negatif terhadap ketepatan waktu pelaporan keuangan.

\section{Profitabilitas Perusahaan}

Profitabilitas merupakan hasil akhir dari sebuah bisnis yang diharapkan oleh pemilik. Adapun faktor ekonomi yang dapat menyebabkan sebuah perusahaan mengalami kerugian ataupun keuntungan (Adebayo \& Adebiyi, 2016). Penyampaian laporan entitas dengan tepat waktu adalah indikator yang menyatakan berita positif dari suatu perusahaan, sedangkan perusahaan dengan berita buruk lebih mungkin untuk menunda penyampaian laporan keuangan (Al-Ajmi, 2008).

Penelitian yang menemukan hasil signifikan negatif antara profitabilitas dengan ketepatan waktu ialah Afify (2009), Efobi dan Okougbo (2010), Eslami et al., (2015), Ismail dan Chandler (2004), Kamarudin et al., (2014), Leventis dan Weetman (2004). Sedangkan Ibadin, Izedonmi, dan Ibadin (2012), Iyoha (2012) dan Moradi, Salehi dan Mareshk ( 2013) tidak menemukan hubungan antara ketepatwaktuan pelaporan keuangan dengan profitabilitas.

$\mathrm{H}_{2}$ : Profitabilitas perusahaan berpengaruh signifikan negatif terhadap ketepatan waktu pelaporan keuangan.

\section{Umur Perusahaan}

Umur perusahaan memiliki dampak terhadap kualitas ketepatan waktu, semakin tua perusahaan maka akan semakin berpotensi cepat dalam menyelesaikan laporan tahunan dibandingkan dengan perusahaan baru karena perusahaan tua telah memiliki prosedur internal kontrol yang kuat (Iyoha, 2012). 
Al-Tahat (2015) pada penelitiannya di Amman Stock Exchange tidak menemukan umur memiliki hubungan secara signifikan terhadap ketepatwaktuan dari pelaporan atau penerbitan laporan keuangan. Namun Al-Shwiyat (2013), Chen-Hui, Chin-Shun dan Victor (2008), Efobi dan Okougbo (2010), Hamidi dan Rasouli (2016) menemukan hasil signifikan positif antara ketepatan waktu pelaporan keuangan dengan umur perusahaan.

$\mathrm{H}_{3}$ : Umur perusahaan berpengaruh signifikan positif terhadap ketepatan waktu pelaporan keuangan.

\section{Leverage}

Leverage untuk mengetahui seberapa jauh sebuah perusahaan bergantung pada liabilitas dalam membiayai aset perusahaan, pihak manajemen perusahaan akan canderung menunda pelaporan keuangan jika berisi nilai buruk. Semakin tinggi nilai leverage maka manajer akan memperlambat penyampaian laporan keuangan (Rezaei \& Shahroodi, 2015).

Ibadin et al., (2012), Mouna dan Anis (2013) menemukan hasil tidak signifikan antara leverage dengan ketepatan waktu pada penelitiannya. Namun pada penelitian Akle (2011), Khasharmeh dan Aljifri (2010) menemukan leverage memiliki efek signifikan negatif terhadap ketepatwaktuan. Hasil penelitian yang ditemukan oleh Adebayo dan Adebiyi (2016), Al-Shwiyat (2013), Ismail dan Chandler (2004), Kamarudin et al., (2014) menemukan leverage dan ketepatan waktu pelaporan keuangan berpengaruh signifikan positif.

$\mathrm{H}_{4}$ : Leverage berpengaruh signifikan positif terhadap ketepatan waktu pelaporan keuangan.

\section{Komite Audit Independensi}

Teori Agensi menyatakan bahwa anggota independen komite audit bisa membantu principal untuk memantau kegiatan para direksi dan mengurangi penahanan informasi, komite audit dengan anggota independen akan dianggap sebagai kelompok yang handal dalam memantau perusahaan (Hashim \& Rahman, 2011). Jumlah anggota komite audit independen lebih banyak maka akan semakin efektif mengurangi terjadinya manajemen laba dan mendorong pelaporan tepat waktu (Oussii \& Taktak, 2016).

Oussii dan Taktak menemukan hubungan tidak signifikan antara ketepatan waktu dengan komite audit independensi. Berbeda dengan penelitian Kamarudin et al., (2014), Yadirichukwu dan Ebimobowei (2013) menemukan komite audit independensi memiliki efek signifikan positif terhadap ketepatwaktuan. Namun Puasa et al., (2014) menemukan komite audit independensi berpengaruh signifikan negatif terhadap ketepatwaktuan dari penerbitan laporan keuangan.

$\mathrm{H}_{5}$ : Komite audit independensi berpengaruh signifikan negatif terhadap ketepatan waktu pelaporan keuangan.

\section{Jumlah Komite Audit}

Peraturan Otoritas Jasa Keuangan nomor 55/POJK.04/2015 menyatakan bahwa "komite audit bertanggung jawab kepada dewan komisaris, komite audit terdiri dari sekurang-kurangnya beranggota tiga orang dengan satu orang komisaris independen dan dua orang anggota lainnya yang berasal dari luar perusahaan”. Jumlah komite audit dalam sebuah perusahaan yang semakin banyak maka akan semakin tepat pada waktunya dalam menyelesaikan laporan keuangannya karena komite audit akan bekerja secara optimal dan efisien dalam menghasilkan laporan dan informasi secara tepat waktu (Kamarudin et al., 2014).

Yadirichukwu dan Ebimobowei
(2013) pada penelitiannya tidak menemukan kaitan antara jumlah komite audit dengan ketepatan waktu. Sedangkan Kamarudin et al., (2014), Puasa et al., (2014) menemukan jumlah komite audit hubungan signifikan negatif terhadap ketepatwaktuan laporan keuangan. 
$\mathrm{H}_{6}$ : Jumlah komite audit berpengaruh signifikan negatif terhadap ketepatan waktu pelaporan keuangan.

\section{Komite Audit Pengalaman}

Komite audit dapat dikatakan pengalaman jika memiliki pengalaman kerja dibidang keuangan serta memiliki profesi akuntansi seperti MIA, ACCA, CPA dan lainnya. Perusahaan yang mungkin akan curang dalam pelaporan keuangan yang memiliki sedikit anggota komite audit yang berpengalaman di bidang akuntasi (Mohamad-Nor et al., 2010).

Komite audit yang berpengalaman di bidang akuntansi akan lebih mengerti tentang risiko dan seberapa lama proses audit pada prosedur audit. Hal ini yang dapat membantu auditor lebih cepat dalam penyelesaikan tugasnya sehingga laporan akan semakin cepat dalam tahap penyelesaian (Yadirichukwu \& Ebimobowei, 2013).

Oussii dan Taktak (2016), Puasa et al., (2014), serta Tazik dan Mohamed (2014) yang melakukan penelitian di Malaysia menemukan komite audit pengalaman berpengaruh signifikan negatif terhadap ketepatan waktu laporan keuangan

$\mathrm{H}_{7}$ : Komite audit pengalaman berpengaruh signifikan negatif terhadap ketepatan waktu pelaporan keuangan.

\section{Jenis Auditor}

Perusahaan yang diaudit oleh auditor Big4 akan lebih cepat penyampaian laporan keuangan entitas dibandingkan dengan auditor selain Big4, karena auditor yang termasuk Big4 lebih efisien dan fleksibel dalam proses mengaudit dan menyelesaikan tugasnya dengan lebih cepat (Gilling, 1977).

Gulec (2017) pada penelitiannya di Turki menemukan hasil signifikan positif antara ketepatan waktu dengan jenis auditor. Sedangkan yang menemukan jenis auditor berpengaruh signifikan negatif terhadap ketepatan waktu pelaporan adalah Abdullah (2007), Ahmed (2003), Ha et al., (2018) namun Afify (2009), Chen-Hui et al., (2008) dan Iyoha (2012) tidak menemukan hubungan signifikan pada jenis auditor dengan ketepatan waktu.

$\mathrm{H}_{8}$ : Jenis auditor berpengaruh signifikan negatif terhadap ketepatan waktu pelaporan keuangan.

\section{Laporan Audit}

Laporan audit termasuk dalam bagian dari laporan tahunan yang diterbitkan oleh pihak auditor yang menyatakan laporan keuangan telah disajikan sesuai dengan PSAK yang disertai dengan opini audit. Hasil penelitian menunjukkan adanya hubungan antara laporan audit dengan ketepatwaktuan dari pelaporan atau penerbitan laporan keuangan (Al-Juaidi \& Al-Afifi, 2016).

Ibadin et al., (2012) meneliti hubungan GCG, atribut perusahaan dan ketepatan waktu di Nigeria, menemukan laporan audit memiliki efek signifikan positif terhadap ketepatwaktuan dalam pelaporan atau penerbitan laporan keuangan. Sedangkan Owusu-Ansah (2000) menemukan laporan audit tidak berkaitan terhadap ketepatan waktu pelaporan keuangan.

$\mathrm{H}_{9}$ : Laporan audit berpengaruh signifkan positif terhadap ketepatan waktu pelaporan keuangan.

\section{Rotasi Auditor}

Rotasi auditor adalah pergantian auditor eksternal yang dilakukan pada beberapa waktu tertentu agar meningkatkan kualitas audit, perusahaan yang melakukan rotasi auditor dengan telat bisa menyebabkan terjadi negosiasi opini ataupun pembelian opini antara perusahaan dengan auditor. Pergantian auditor dapat mengurangi keterlambatan peyelesaian audit jika auditor tersebut memahami proses audit, prosedur audit dan sistem dari klien (Dibia \& Onwuchekwa, 2013). Patrick dan Benjamin (1994) melakukan penelitian di Hong Kong menemukan rotasi auditor berpengaruh signifikan positif terhadap ketepatan waktu pelaporan keuangan. 
$\mathrm{H}_{10}$ : Rotasi auditor berpengaruh signifikan positif terhadap ketepatan waktu pelaporan keuangan.

\section{Opini Audit}

Opini audit didefinisikan sebagai pernyataan yang dikeluarkan oleh pihak auditor pada saat selesai dalam melakukan proses audit ataupun berupa pernyatan informasi keuangan yang disajikan telah wajar sesuai dengan keadaan sebernarnya. Perusahaan yang tidak menerima opini audit unqualified akan lebih cenderung menunda penyampaian laporan tahunan perusahaan dibandingkan dengan entitas yang menerima opini unqualified (Soltani, 2002).

Penelitian yang dilakukan oleh Daoud et al., (2014), Dwyer dan Wilson (1989) dan Turel (2010) menemukan opini audit memiliki efek signifikan negatif terhadap ketepatwaktuan dari pelaporan atau penerbitan laporan keuangan. Namun Abdullah (2007), Moradi et al., (2013), Pourali et al., (2013) menemukan opini audit memiliki dampak signifikan positif terhadap ketepatan waktu.

$\mathrm{H}_{11}$ : Opini audit berpengaruh signifikan positif terhadap ketepatan waktu pelaporan keuangan.

\section{METODOLOGI PENELITIAN}

Objek pada penelitian ini adalah perusahaan yang telah diaudit dan telah mempublikasikan laporan tahunan di BEI dengan rentang tahun 2012-2017.
Metode pemilihan data pada penelitian ini adalah pemilihan sampel bertujuan, pemilihan sampel dengan kriteria tertenru (Indriantoro \& Supomo, 2015). Adapun kriteria yang harus dipenuhi untuk penelitian ini adalah:

1. Perusahaan telah menerbitkan atau menyampaikan laporan keuangan tahunan entitas dan tercantum di BEI pada tahun 2012-2017

2. Laporan keuangan tahunan yang diaudit oleh KAP pada tahun 20122017

3. Laporan tahunan entitas yang menyediakan informasi dan datadata yang diperlukan untuk mengukur variabel dependen dan independen.

\section{Variabel Dependen}

Variabel dependen pada penelitian ini yaitu ketepatan waktu dari pelaporan atau penerbitan laporan keuangan yang diukur dengan jumlah hari dari tanggal akhir tahun fiskal sampai dengan tanggal laporan keuangan tahunan bisa digunakan oleh pengguna informasi (Al-Juaidi \& AlAfifi, 2016).

Timeliness $=$ jumlah hari dari tanggal akhir tahun fiskal sampai dengan tanggal penerbitan laporan keuangan tahunan ke OJK / BEI (Al-Juaidi \& Al-Afifi, 2016). 
Tabel 1

Variabel independen

\begin{tabular}{|c|c|c|}
\hline Variabel Independen & Keterangan & Sumber \\
\hline Ukuran perusahaan & Logaritma total aset & (Ohaka \& Akani, 2017) \\
\hline Profitabilitas perusahaan & $\mathrm{EPS}=\frac{\text { Laba bersih }}{\text { Jumlah lembar saham beredar }}$ & (Ohaka \& Akani, 2017) \\
\hline Umur perusahaan & Jumlah tahun dari tahun perusahaan berdiri & (Efobi \& Okougbo, 2010) \\
\hline Leverage & Lev $=\frac{\text { Total liabilitas }}{\text { Total aset }}$ & (Rezaei \& Shahroodi, 2015) \\
\hline Komite audit independensi & $\mathrm{KAI}=\frac{\text { Jumlah anggota independen }}{\text { Total anggota komite audit }}$ & (Puasa et al., 2014) \\
\hline Jumlah komite audit & Jumlah anggota audit perusahaan & (Al-Juaidi \& Al-Afifi, 2016) \\
\hline Komite audit pengalaman & $\mathrm{KAP}=\frac{\text { Jumlah komite pengalaman }}{\text { Jumlah anggota komite audit }}$ & (Tazik \& Mohamed, 2014) \\
\hline Jenis auditor & '1' jika Big4 dan '0' lainnya & (Vuran \& Adiloglu, 2013) \\
\hline Laporan audit & $\begin{array}{l}\text { Dari } 31 \text { Des sampai tanggal penerbitan laporan } \\
\text { audit eksternal }\end{array}$ & (Ibadin et al., 2012) \\
\hline Rotasi auditor & $\begin{array}{l}\text { ' } 1 \text { ' jika rotasi auditor dan '0' tidak melakukan } \\
\text { rotasi auditor }\end{array}$ & (Al-Juaidi \& Al-Afifi, 2016) \\
\hline Opini audit & '1' jika opini unqualified dan '0' opini lainnya & (Daoud et al., 2014) \\
\hline
\end{tabular}

Sumber: Data sekunder diolah (2018).

\section{HASIL PENELITIAN}

\section{Statistik Deskriptif}

Tabel 2

Hasil Uji Statistik Deskriptif

\begin{tabular}{|l|c|c|c|c|c|}
\hline & $\mathbf{N}$ & Minimal & Maksimal & Rata-rata & Std. Deviasi \\
\hline Timeliness & 1.618 & 70 & 178 & 120,02 & 9,967 \\
\hline C.SIZE (Milyar Rupiah) & 1.618 & 10,35048 & $750.319,671$ & $15.594,9489$ & $49.725,96108$ \\
\hline C.PROF & 1.618 & $-1.124,55759$ & $55.587,5178$ & 180,53518 & $1.550,86153$ \\
\hline C.AGE & 1.618 & 4 & 158 & 33,38 & 16,973 \\
\hline LEV & 1.618 & 0,00032 & 8,30773 & 0,55439 & 0,52398 \\
\hline ACI & 1.618 & 0 & 1 & 0,88302 & 0,24643 \\
\hline No.AC & 1.618 & 0 & 7 & 3,1 & 0,507 \\
\hline ACE & 1.618 & 0 & 1 & 0,88237 & 0,21548 \\
\hline AReport & 1.618 & 11 & 179 & 75,34 & 16,087 \\
\hline Valid N (listwise) & 1.618 & & & & \\
\hline
\end{tabular}

Sumber: Data sekunder diolah (2018).

Tabel 3

Hasil Uji Statistik Deskriptif Variabel Dummy

\begin{tabular}{|l|l|c|c|}
\hline Variabel & \multicolumn{1}{|c|}{ Kategori } & Frekuensi & Persentase \\
\hline Jenis auditor & $0=$ Otherwise & 930 & 57.5 \\
\hline & $1=$ Big4 & 688 & 42.5 \\
\hline Rotasi auditor & $0=$ Rotasi & 829 & 51.2 \\
\hline & $1=$ Tidak rotasi & 789 & 48.8 \\
\hline Opini audit & $0=$ Otherwise & 602 & 37.2 \\
\hline & $1=$ Unqualified & 1016 & 62.8 \\
\hline
\end{tabular}

Sumber: Data sekunder diolah (2018).

Program Studi Akuntansi, Fakultas Ekonomi, Universitas Internasional Batam | 21 
Nilai rata-rata sebesar 120,02 yang berarti perusahaan yang tercatat di BEI ratarata 120 hari dalam penyampaian laporan keuangannya setelah tanggal tutup buku perusahaan. Peraturan Otoritas Jasa Keuangan nomor 29/POJK.04/2016, ratarata perusahaan yang terdaftar di BEI pada periode 2012-2017 menyampaikan laporan keuangan tahunan telah sesuai dengan aturan yang berlaku.

Variabel jenis auditor menunjukkan bahwa terdapat 930 data yang diaudit oleh KAP selain Big4 sedangkan data perusahaan yang diaudit oleh KAP Big4 sebanyak 688 data. Perusahaan yang tercantum di BEI pada tahun 2012-2017 Tabel 4

Hasil Uji Chow

\begin{tabular}{cc}
\hline Effects Test & Prob. \\
\hline Cross-section Chi-square & 0,0000 \\
\hline
\end{tabular}

Sumber: Data sekunder diolah (2018).

Tabel 5

Hasil Uji Hausman

\begin{tabular}{cc}
\hline Test Summary & Prob. \\
\hline Cross-section random & 0,0000 \\
\hline
\end{tabular}

Sumber: Data sekunder diolah (2018).

Dari hasil uji Chow menunjukkan bahwa model yang lebih tepat digunakan antara pooled OLS dan Least Squares Dummy Variable Regression Model (LSDV) adalah

LSDV. Kemudian dilanjutkan dengan uji Hausman. Hasil pemilihan model terbaik adalah model FEM.

Tabel 6

Hasil Uji F

\begin{tabular}{ccc}
\hline Variabel Dependen & Sig & Kesimpulan \\
\hline Ketepatan waktu pelaporan keuangan & 0,0000 & Signifikan \\
\hline
\end{tabular}

Sumber: Data sekunder diolah (2018). 
Tabel 7

Hasil Uji $t$

\begin{tabular}{|c|c|c|c|}
\hline Variabel & Koefisien & Sig & Kesimpulan \\
\hline C & 66,86154 & 0,0086 & \\
\hline C_SIZE & $-0,125383$ & 0,9542 & Tidak dapat dibuktikan (tidak signifikan) \\
\hline C_PROF & 0,00017 & 0,2982 & Tidak dapat dibuktikan (tidak signifikan) \\
\hline C_AGE & 1,834609 & $0,0000^{*}$ & Dapat dibuktikan (signifikan positif) \\
\hline LEV & $-0,565557$ & 0,5790 & Tidak dapat dibuktikan (tidak signifikan) \\
\hline ACI & $-11,83833$ & $0,0219^{*}$ & Dapat dibuktikan (signifikan negatif) \\
\hline NO_AC & $-2,09676$ & $0,0174^{*}$ & Dapat dibuktikan (signifikan negatif) \\
\hline ACE & 0,930945 & 0,7059 & Tidak dapat dibuktikan (tidak signifikan) \\
\hline BIG4 & $-0,956207$ & 0,6034 & Tidak dapat dibuktikan (tidak signifikan) \\
\hline AREPORT & 0,125118 & $0,0000^{*}$ & Dapat dibuktikan (signifikan positif) \\
\hline AROTATION & 0,299689 & 0,5200 & Tidak dapat dibuktikan (tidak signifikan) \\
\hline OPINI & 1,161519 & 0,0789 & Tidak dapat dibuktikan (tidak signifikan) \\
\hline
\end{tabular}

Note * : Significant at the 0.05 level

Sumber:Data sekunder yang diolah (2018).

\section{$\mathrm{H}_{1}$ :}

Hasil hipotesis pertama menunjukkan nilai koefisien $-0,125383$ yang artinya setiap peningkatan satu rupiah nilai total aset maka akan menurunkan keterlambatan pelaporan sebesar 0,1254 hari. Nilai signifikan 0,9542 berarti variabel ukuran perusahaan tidak berkaitan dengan ketepatwaktuan dari pelaporan atau penerbitan laporan keuangan entitas. Hal ini mengindikasikan bahwa nominal nilai total aset tidak berpengaruh terhadap ketepatan waktu dalam pelaporan keuangan entitas. Besar atau kecil skala perusahaan jika tidak memiliki staf yang handal dalam penyusunan laporan maka akan menghambat penyelesaian laporan keuangan dengan tepat waktu (Al-Juaidi \& Al-Afifi, 2016). Hipotesis $1\left(\mathrm{H}_{1}\right)$ tidak dapat dibuktikan, penelitian ini bertolak belakang dengan Adebayo dan Adebiyi (2016), Ahmad et al., (2016), Akle (2011), Al-Ajmi (2008). Namun hasil penelitian ini didukung oleh Al-Juaidi dan Al-Afifi (2016), Al-Tahat (2015), Ibadin et al., (2012), serta Iyoha (2012).
$\mathbf{H}_{2}$ :

Variabel profitabilitas perusahaan yang diukur dengan nilai laba bersih dibagi jumlah saham beredar menunjukkan nilai koefisien 0,00017 artinya setiap kenaikan satu rupiah dari nilai EPS maka penyelesaian laporan keuangan akan lebih cepat 0,00017 hari. Nilai signifikan 0,2982 menunjukkan profitabilitas perusahaan tidak memiliki kaitan terhadap ketepatwaktuan dalam penerbitan laporan entitas. Hipotesis $2 \quad\left(\mathrm{H}_{2}\right)$ tidak dapat dibuktikan, hasil penelitian sejalan dengan Ibadin et al., (2012), Iyoha (2012), serta Moradi et al., (2013) yang memperoleh hasil hubungan antara profitabilitas dengan ketepatan waktu tidak berpengaruh signifikan.

H3:

Hasil hipotesis 3 menunjukkan variabel umur yang diukur dengan selisih tahun sekarang dengan tahun berdirinya perusahaan. Hasil signifikan membuktikan 0,0000 dan nilai koefisien 1,834609 menunjukkan positif sehingga umur 
perusahaan memiliki dampak signifikan positif terhadap ketepatwaktuan dalam penyampaian laporan entitas yang disebabkan semakin umur perusahaan menjadi tua maka prosedur pengendalian internal perusahaan akan kuat sehingga akan membantu pihak auditor lebih cepat dalam penyelesaikan prosedur audit, sehingga keterlambatan penyampaian laporan keuangan tahunan akan semakin berkurang (Iyoha, 2012). Hipotesis $3\left(\mathrm{H}_{3}\right)$ dapat dibuktikan dan hasil penelitian didukung oleh Al-Shwiyat (2013), ChenHui et al., (2008), Efobi dan Okougbo (2010) serta Iyoha (2012) namun hasil penelitian bertolak belakang dengan Owusu-Ansah (2000) Al-Tahat (2015) dan Moradi et al., (2013)

\section{H4:}

Variabel leverage yang diukur dengan total liabilitas dibagi total aset membuktikan nilai koefisien -0,565557 yang artinya setiap kenaikan nilai leverage sebesar satu maka dapat mengurangi keterlambatan dalam pelaporan sebesar 0,5656 hari. Signifikansi sebesar 0,5790 berarti variabel leverage tidak memiliki pengaruh signifikan. Seberapa mampu atau tidak mampu perusahaan membayar kewajiban dengan aset yang dimiliki tidak berpengaruh terhadap ketepatwaktuan dari pelaporan atau penerbitan laporan keuangan, karena nilai leverage berfungsi untuk mengetahui tingkat kapabilitas perusahaan dalam melunasi kewajibannya dengan total aset yang dimiliki. Hipotesis 4 $\left(\mathrm{H}_{4}\right)$ tidak dapat dibuktikan, hasil uji ini didukung oleh Gulec (2017), Ibadin et al., (2012), Mouna dan Anis (2013) Namun hasil penelitian berlawanan dengan Adebayo dan Adebiyi (2016), Al-Ajmi (2008) dan Al-Shwiyat (2013)

\section{H5:}

Hasil hipotesis 5 merupakan variabel komite audit independensi yang dengan pengukuran anggota komite audit independen dibagi seluruh anggota komite audit yang terdapat dalam perusahaan, nilai koefisien -11,83833 menunjukkan negatif dengan tingkat signifikan 0,0219 yang artinya komite audit independensi memiliki efek signifikan negatif terhadap ketepatan waktu. Komite audit independensi dibentuk agar menjaga informasi yang disajikan bersifat independen dan tidak terjadi kerjasama antar pihak manajemen, komisaris, akuntan, audit internal dan staf lainnya. Semakin banyak anggota indepeden dalam komite audit, dapat membantu komisaris dalam pengawasan yang bersifat independen maka akan mengurangi keterlambatan dalam penyampaian laporan keuangan (Puasa et al., 2014). Hipotesis $5 \quad\left(\mathrm{H}_{5}\right)$ dapat dibuktikan dan hasil penelitian sejalan dengan Puasa, Salleh dan Ahmad (2014). Namun bertolak belakang dengan Kamarudin et al., (2014), Yadirichukwu dan Ebimobowei (2013), Oussii dan Taktak (2016).

\section{H6:}

Hasil hipotesis 6 merupakan variabel jumlah komite audit yang diukur dengan jumlah keseluruhan komite audit yang diumumkan perusahaan menunjukkan nilai koefisien negatif $\quad-2,09676$ dengan nilai signifikan 0,0174 yang artinya komite audit berpengaruh secara signifikan negatif terhadap ketepatwaktuan dalam pelaporan atau penerbitan laporan keuangan entitas. Banyaknya jumlah komite audit pada sebuah perusahaan dapat meningkatkan pengawasan terhadap perusahaan, sehingga dapat mempercepat penyampaian dan penerbitan laporan keuangan. Semakin bertambah jumlah komite audit perusahaan maka akan mampu mengurangi keterlambatan dalam pelaporan keuangan perusahaan (Puasa et al., 2014). Hipotesis $6\left(\mathrm{H}_{6}\right)$ dapat dibuktikan, hasil penelitian selaras dengan Kamarudin et al., (2014) Puasa et al., (2014). Akan tetapi hasil penelitian bertolak belakang dengan Oussii dan Taktak (2016), Yadirichukwu dan Ebimobowei (2013) 


\section{$\mathbf{H}_{7}$ :}

Hasil hipotesis 7 mengenai variabel komite audit pengalaman yang diukur dengan komite pengalaman dibagi seluruh anggota komite audit perusahaan menunjukkan nilai koefisien 0,930945 yang artinya bertambahnya satu orang anggota komite audit yang berpengalaman dapat mempercepat penyelesaian sebesar 0,931 hari. Nilai signifikan 0,7059 menunjukkan komite audit pengalaman tidak berpengaruh secara signifikan terhadap ketepatwaktuan dari pelaporan keuangan. Hipotesis $7\left(\mathrm{H}_{7}\right)$ tidak dapat dibuktikan, komite audit yang berpengalaman maupun yang tidak berpengalaman dalam bidangnya tidak dapat mempengaruhi ketepatwaktuan dari penyampaian laporan keuangan entitas, dikarenakan perusahaan yang memiliki komite audit pengalaman tidak bertanggung jawab atas penyelesaian laporan keuangan. Melainkan komite audit pengalaman membantu memberikan pendapat jika terjadi perbedaan pendapat antara manajemen dengan akuntan serta pengawasan terhadap proses akuntansi yang berkaitan (OJK, 2015). Hasil penelitian bertolak belakang dengan Oussii dan Taktak (2016), Puasa et al., (2014), Tazik dan Mohamed (2014) Yadirichukwu dan Ebimobowei (2013) Namun didukung oleh Apadore dan Noor (2013).

\section{H8:}

Hasil hipotesis 8 merupakan variabel jenis auditor menunjukkan nilai signifikan 0,6034 yang artinya jenis auditor tidak berpengaruh signifikan terhadap ketepatwak tuan dari penerbitan laporan keuangan. Tanggung jawab dari seorang auditor adalah untuk menyatakan opini audit dari hasil perusahaan yang diaudit. Perusahaan yang memilih Big4 sebagai auditor belum tentu cepat dapat menyelesaikan prosedur audit ataupun menyatakan opini dibandingkan dengan Non-big4. Auditor yang termasuk kategori Big4 tidak hanya mengaudit satu perusahaan saja namun banyak perusahaan, sehingga dapat menyebabkan pihak auditor terlambat dalam penyelesaian laporan audit. Namun auditor yang Non-big4 yang memiliki lebih sedikit klien dan dapat lebih cepat menyelesaikan prosedur audit serta laporan audit, akan tetapi perusahaan diaudit oleh auditor Non-big4 pada hasil pernyataan dalam laporan audit dapat diragukan oleh pihak investor maupun pengguna informasi (Carbaja \& Yadnyana, 2015). Hipotesis $8\left(\mathrm{H}_{8}\right)$ tidak dapat terbukti. Hasil penelitian sejalan dengan Afify (2009), Al-Ajmi (2008), Chen-Hui et al., (2008) dan Iyoha (2012) Hasil penelitian bertolak belakang dengan Abdullah (2007), Ahmed (2003), Ashton et al., (1989) dan Gulec (2017)

\section{H9:}

Variabel laporan audit dengan nilai koefisien 0,125118 positif dan signifikan 0,0000 yang artinya laporan audit memiliki hubungan signifikan positif terhadap penerbitan laporan keuangan secara tepat waktu sehingga Hipotesis $9\left(\mathrm{H}_{9}\right)$ dapat dibuktikan. Semakin cepat penerbitan laporan audit oleh auditor maka semakin cepat juga laporan keuangan tahunan dapat diterbitkan oleh perusahaan, karena laporan audit merupakan bagian dari laporan tahunan. Penelitian ini selaras dengan Ibadin et al., (2012) sedangkan hasil penelitian bertentangan dengan penelitian yang dilakukan Owusu-Ansah (2000).

\section{H10:}

Hasil hipotesis 10 menujukkan variabel rotasi auditor yang diukur dengan variabel dummy menunjukkan tingkat signifikan 0,5200 artinya rotasi auditor tidak berpengaruh signifikan terhadap katepatan waktu dari pelaporan keuangan. Apabila Perusahaan tidak melakukan pergantian atau rotasi auditor belum dapat dipastikan dapat menerbitkan laporan keuangan dengan tepat pada waktunya. Sebaliknya perusahaan yang memilih melakukan pergantian auditor juga ingin melaporkan dengan tepat waktu, karena tujuan dari laporan diterbitkan dengan cepat dan tepat waktu agar pengguna informasi 
memperoleh informasi kinerja perusahaan dengan cepat dan tidak kehilangan manfaat dari informasi yang disajikan tersebut (Mareta, 2015). Hipotesis $10\left(\mathrm{H}_{10}\right)$ tidak dapat dibuktikan dan hasil penelitian ini dibuktikan juga oleh Dibia dan Onwuchekwa (2013). Namun hasil berbeda pada penelitian Patrick dan Benjamin (1994)

\section{H11:}

Hasil hipotesis 11 menunjukkan variabel opini audit yang diukur dengan variabel dummy menunjukkan tingkat signifikan 0,0789 artinya opini audit tidak berpengaruh secara signifikan. Laporan yang diberi opini unqualified ataupun selain unqualified tidak berpengaruh terhadap penerbitan laporan tahunan. Apabila selama pengerjaan lapangan yang dilakukan oleh pihak auditor tidak terjadi masalah dan semua bukti telah sesuai dengan keadaan sebenarnya maka pihak auditor dapat dengan cepat dalam menyatakan opini audit baik opini uqualified ataupun selain unqualified (Mareta, 2015). Hipotesis 11 $\left(\mathrm{H}_{11}\right)$ tidak terbukti, hasil penelitian selaras dengan Khasharmeh dan Aljifri (2010)
Namun hasil penelitian berbeda dengan Abdullah (2007), dan Pourali et al., (2013).

Berdasarkan dari hasil pengujian t, disajikan persamaan statistika untuk penelitian sebagai berikut:

Timeliness $=66,86154$

0,125383 C_SIZE $+0,00017$ C_PROF + 1,834609C_AGE - 0,565557LEV $11,83833 \mathrm{ACI}$ - 2,096762NO_AC + 0,930945ACE - 0,956207BIG4 + 0,125118AREPORT + 0,299689AROTA + 1,161519 OPINI $+\mathrm{e}$

Dimana:

Timeliness $=$ Ketepatan waktu dalam pelaporan keuangan

C_SIZE = Ukuran perusahaan

C_PROF = Profitabilitas perusahaan

C_AGE $=$ Umur perusahaan

LEV $=$ Leverage

ACI $=$ Komite audit independen

NO_AC = Jumlah komite audit

$\mathrm{ACE} \quad=$ Komite audit pengalaman

BIG4 = Jenis auditor

AREPORT = Laporan audit

AROTA $=$ Rotasi auditor

OPINI $=$ Opini audit

$\mathrm{e} \quad=$ Error

Tabel 5

Hasil Uji Adjusted $R^{2}$

\begin{tabular}{|c|c|}
\hline Variabel Dependen & Adjusted R Square \\
\hline Ketepatan waktu pelaporan keuangan & 0,235054 \\
\hline
\end{tabular}

Berdasarkan hasil uji pada tabel 5, hasil uji Adjusted $\mathrm{R}^{2}$ menunjukkan nilai sebesar 0,235054 atau 23,51\%, yang artinya variabel independen menjelaskan variabel ketepatan waktu dalam pelaporan atau penerbitan laporan keuangan sebesar $23,51 \%$ sedangkan $76,49 \%$ lainnya dipengaruhi oleh faktor lain yang tidak tercantum dalam model penelitian ini seperti ukuran dewan, pengalaman dewan dan pertemuan dewan (Eslami et al., 2015).

\section{KESIMPULAN}

Penelitian ini memiliki tujuan untuk mengetahui determinan-determinan yang memberi efek secara signifikan dengan timeliness reporting. Berdasarkan hasil uji dari penelitian ini dapat disimpulkan bahwa:

1. Rata-rata perusahaan yang tercatat di BEI pada periode 2013-2017 memerlukan 120 hari dalam penyampaian serta penerbitan laporan keuangan tahunan dimana artinya peraturan Otoritas Jasa Keuangan nomor 29/POJK.04/2016 mengenai penyampaian laporan perusahaan publik telah dipatuhi perusahaan.

Program Studi Akuntansi, Fakultas Ekonomi, Universitas Internasional Batam | 26 
2. Hasil penelitian menemukan umur dan laporan audit memiliki hubungan signifikan positif terhadap timeliness.

3. Audit komite independensi dan jumlah anggota komite audit memiliki efek negatif terhadap timeliness.

4. Ukuran perusahaan, profitabilitas perusahaan, leverage, opini audit komite audit pengalaman, jenis auditor, rotasi auditor tidak berkaitan dengan timeliness.

Adapun rekomendasi untuk peneliti berikut adalah penelitian selanjutnya dapat berfokus pada perusahaan keluarga dimana perusahaan keluarga memiliki permasalahan agensi dan manajemen yang berbeda pada perusahaan non-keluarga dan menambah konstruk ataupun variabel lainnya yang mungkin akan berpengaruh terhadap ketepatan waktu dalam penerbitan laporan tahunan seperti board independence, board size, pertemuan komite audit dan besarnya audit fee.

\section{DAFTAR PUSTAKA}

Abdullah, S.-N. (2007). Board composition, audit committee and timeliness of corporate financial report in Malaysia. Journal Corporate Ownership \& Control, 4(2), 33-45.

Adebayo, P. A., \& Adebiyi, W. K. (2016). Effect of firm characteristics on the timeliness of corporate financial reporting: Evidence from Nigerian deposit money banks. International Journal of Economics, Commerce and Management, 4(3), 369-381.

Ahmed, K. (2003). The timeliness of corporate reporting: A comparative study of South Asia. Advances in International Accounting, 16, 17-43.

Afify, H. A. E. (2009). Determinants of audit report lag: Does implementing corporate governance have any impact? Empirical evidence from Egypt. Journal of Applied Accounting Research, 10(1).

Akle, Y. H. (2011). The relationship between financial reporting timeliness and attributes of companies listed on Egyptian Stock Exchange "An empirical study." Internal Auditing \& Risk Management, 3(23), 83-103.

Al-Ajmi, J. (2008). Audit and reporting delays: Evidence from an emerging market. International Journal of Cardiology, 24(2), 217-226.

Al-Juaidi, D. O., \& Al-Afifi, D. A. A. M. (2016). The factors affecting timeliness of corporate financial reporting: Empirical evidence from the Palestinian and Amman Stock Exchange. International Journal of Management Sciences and Business Research, 5(10).

Al-Shwiyat, Z. M. M. (2013). Affecting factors on the timing of the issuance of annual financial reports "Empirical study on the Jordanian public shareholding companies." European Scientific Journal, 9(22).

Al-Tahat, S. S. Y. (2015). Timeliness of audited financial reports of Jordanian listed companies. IPASJ International Journal of Management (IIJM), 3(2), 39-47.

Chen-Hui, W., Chin-Shun, W., \& Victor, L. W. (2008). The release timing of annual report and board characteristics. The International Journal of Business and Finance Research, 2(1), 103-118.

Courtis, J. K. (1976). Relationships between timeliness in corporate reporting and corporate attributes. Accounting and Business Research, 7(25), 45-56.

Dibia, D. N. ., \& Onwuchekwa, J. . (2013). An examination of the audit report lag of companies quoted in the Nigeria Stock Exchange. International Journal of Business and Social Science (IJBSR), 3(9), 8-16.

Dwyer, P. D., \& Wilson, E. R. (1989). An empirical investigation of factors affecting the timeliness of reporting by municipalities. Journal of Accounting and Public Policy, 8, 29-55. 
Dyer, J. C., \& McHugh, A. J. (1975). The timeliness of the australian annual report. Journal of Accounting Research, 13(2), 204-219.

Efobi, U., \& Okougbo, P. (2010). Timeliness of financial reporting in Nigeria. South African Journal of Accounting Research, 2, 1-16.

Eslami, R., Armin, A., \& Jaz, H. R. (2015). A study on the effect of corporate governance on the timeliness of financial reports of listed firms on Tehran Stock Exchange. Academic Journal of Accounting and Economic Researches, 4(4), 140-152.

Gilling, D. M. (1977). Timeliness in corporate reporting: Some further comment. Accounting and Business Research, 8(29), 34-36.

Gulec, O. F. (2017). Timeliness of corporate reporting in developing economies: Evidence from Turkey. Accounting and Management Information Systems, 16(3), 219-239.

Ha, H. T. V., Hung, D. N., \& Phuong, N. T. T. (2018). The study of factors affecting the timeliness of financial reports: The experiments on listed companies in Vietnam. Asian Economic and Financial Review, 8(2),294-307.

Hamidi, G., \& Rasouli, H. (2016). Evaluation of the relationship between accounting variables and timelines of annual reports of accepted companies in Tehran Stock Exchange. Mediterranean Journal of Social Scienes, 7(4).

Ibadin, I. M., Izedonmi, F., \& Ibadin, P. O. (2012). The association between selected corporate governance attributes, company attributes and timeliness of financial reporting in Nigeria. Research Journal of Financial and Accounting, 3(9), 137145.

Ikatan Akuntan Indonesia. (2017). Standar akuntansi indonesia. Jakarta: Dewan Standar Akuntan Indonesia.

Indriantoro, N., \& Supomo, B. (2015).
Metodologi penelitian bisnis untuk akuntansi \& manajemen. Yogyakarta: BPFE.

Ismail, K. N. I. K., \& Chandler, R. (2004). The timeliness of quarterly financial reports of companies in Malaysia. Asian Review of Accounting, 12(1), 118.

Iyoha, F. . (2012). Company attributes and the timeliness of financial reporting in Nigeria. Business Intelligence Journal, 5(1), 41-49.

Khasharmeh, H. A., \& Aljifri, K. (2010). The timeliness of annual reports in Bahrain and the United Arab emirates: An empirical comparative study. The International Journal of Business and Finance Research, 4(1), 51-71.

Leventis, S., \& Weetman, P. (2004). Timeliness of financial reporting: Applicability of disclosure theories in an emerging capital market. Accounting and Business Research, 34(1), 43-56.

Moradi, D. M., Salehi, D. M., \& Mareshk, M. S. (2013). Timeliness of annual financial reporting: Evidence from the Tehran Stock Exchange. $A B A C$ Journal, 33(3), 20-29.

Mouna, A., \& Anis, J. (2013). Financial reporting delay and corporate governance: Evidence from Tunisia. International Journal of Information, Business and Management, 5(4), 3246.

Peraturan Otoritas Jasa Keuangan Nomor 55 /POJK.04/2015 tentang pembentukan dan pedoman pelaksanaan kerja komite audit.

Ohaka, J., \& Akani, F. N. (2017). Timeliness and relevance of financial reporting in Nigerian quoted firms. Management and Organizational Studies, 4(2), 55-62.

Oussii, A. A., \& Taktak, N. B. (2016). Audit committee effectiveness and financial reporting timeliness: The case of Tunisian listed companies. African Journal of Economic and Management Studies.

Retrieved 
from://doi.org/10.1108/AJEMS-112016-0163

Owusu-Ansah, S. (2000). Timeliness of corporate financial reporting in emerging capital markets : Empirical evidence from the Zimbabwe Stock Exchange. Accounting and Business Research, 30(3), 241-254.

Pourali, M. R., Jozi, M., Rostami, K. H., Taherpour, G. R., \& Niazi, F. (2013). Investigation of effective factors in audit delay: Evidence from Tehran Stock Exchange (TSE). Research Journal of Applied Sciences, Engineering and Technology, 5(2), 405-410.

Puasa, S., Salleh, M. F. M., \& Ahmad, A. (2014). Audit committee and timeliness of financial reporting: Malaysian public listed companies. Middle-East Journal of Scientific Research, 22(2), 162-175.

Rezaei, F., \& Shahroodi, P. (2015). The relationship between audit opinion change and timing of disclosure. International Journal of Innovation and Applied Studies, 10(3), 778-790.

Soltani, B. (2002). Timeliness of corporate and audit reports: Some empirical evidence in the French context. The International Journal of Accounting, 37, 215-246.

Tazik, H., \& Mohamed, Z. M. (2014).
Accounting information system effectiveness, foreign ownership and timeliness of corporate financial report. Asia-Pacific Business Research Conference.

Wang, J., \& Song, L. (2006). Timeliness of annual reports of Chinese listed companies. Jounal of Chinese Economic and BuWasiness Studies, 4(3), 37-41.

Yadirichukwu, E. (CNA), \& Ebimobowei, A. (ACA). (2013). Audit committee and timeliness of financial reports: empirical evidence From Nigeria. Journal of Economics and Sustainable Development, 4(20), 14-26.

Vuran, B., \& Adiloglu, B. (2013). Is timeliness of corporate financial reporting related to accounting variables? Evidence from Istanbul Stock Exchange. International Journal of Business and Social Science, 4(6), 58-70. 